Brit. Heart f., 1967, 29, 926.

\title{
Complications in 220 Patients with Cardiac Dysrhyth- mias Treated by Phased Direct Current Shock, and Indications for Electroconversion
}

\author{
LEON RESNEKOV AND LAWSON MCDONALD
}

From The Institute of Cardiology, National Heart Hospital, London W.1

Direct current shock is more effective than alternating current in the treatment of ventricular dysrhythmias (Lown et al., 1962) and is more effective than drug therapy in converting supraventricular dysrhythmias to sinus rhythm (McDonald, Resnekov, and O'Brien, 1964). Although earlier reports stressed the benign nature of the treatment (Lown, 1964; Morris et al., 1964), it has already been shown that it may lead to potentially serious complications (McDonald and Resnekov, 1965; Resnekov and McDonald, 1965). In this paper complications following the use of phased direct current (DC) shock, in the management of 220 consecutive patients with supraventricular dysrhythmias and ventricular tachycardia, are analysed.

\section{SubJeCtS AND METHOdS}

Studies were made on 220 patients (Table I) with atrial fibrillation, atrial flutter, atrial tachycardia, and ventricular tachycardia who were treated with direct current

Received March 21, 1967. shock by methods previously described (McDonald et al., 1964). If the patient was on digitalis, it was stopped for at least 24 hours before treatment. Light general anæsthesia was used in all except 1 patient (Gilston, Fordham, and Resnekov, 1965). The 220 primary episodes of treatment were consecutive, and patients were not excluded because they were too ill. The duration of the dysrhythmias, the, grade of the patient's disability, and the nature and severity of any underlying heart disease were noted at the time of clinical examination. A 12-lead electrocardiogram was recorded in every patient and chest radiographs taken. The cardiothoracic ratio (CTR\%) (Danzer, 1919) was calculated and the size of the left atrium graded (Resnekov, 1965). The erythrocyte sedimentation rate (ESR) was measured by a modification of Westergren's technique (Dawson, 1960). Serum levels of the glutamic oxaloacetic transaminase were measured by the SigmaFrankel technique $(1956,1961)$ and of the lactic dehydrogenase by the technique of Berger and Broida (1957, 1960); the levels of blood urea and serum electrolytes were estimated in all patients receiving diuretic therapy. In any patient who was receiving anticoagulant therapy a thrombotest (Owren, 1959) was used to establish that

TABLE I

DETAILS OF PATIENTS

\begin{tabular}{|c|c|c|c|c|c|}
\hline Heart disease & $\begin{array}{c}\text { Atrial } \\
\text { fibrillation }\end{array}$ & $\begin{array}{l}\text { Atrial } \\
\text { flutter }\end{array}$ & $\begin{array}{c}\text { Atrial } \\
\text { tachycardia }\end{array}$ & $\begin{array}{l}\text { Ventricular } \\
\text { tachycardia }\end{array}$ & Total \\
\hline $\begin{array}{l}\text { Rheumatic: } \\
\text { Post-operative } \\
\text { Not operated } \\
\text { Lone dysrrhythmias } \\
\text { Cardiomyopathy } \\
\text { Ischæmic } \\
\text { Congenital } \\
\text { Treated thyrotoxicosis } \\
\text { Systemic hypertension } \\
\text { Digitalis toxicity }\end{array}$ & $\begin{array}{r}86 \\
15 \\
33 \\
17 \\
16 \\
7 \\
5 \\
1 \\
-\end{array}$ & $\begin{array}{r}\frac{2}{7} \\
2 \\
11 \\
\frac{11}{1} \\
\end{array}$ & $\begin{array}{l}\frac{1}{1} \\
\frac{4}{4} \\
\frac{1}{1}\end{array}$ & $\begin{array}{l}\bar{Z} \\
\frac{1}{6} \\
= \\
=\end{array}$ & $\begin{array}{r}89 \\
41 \\
20 \\
25 \\
22 \\
5 \\
2 \\
1\end{array}$ \\
\hline Total & 180 & 24 & 9 & 7 & 220 \\
\hline
\end{tabular}




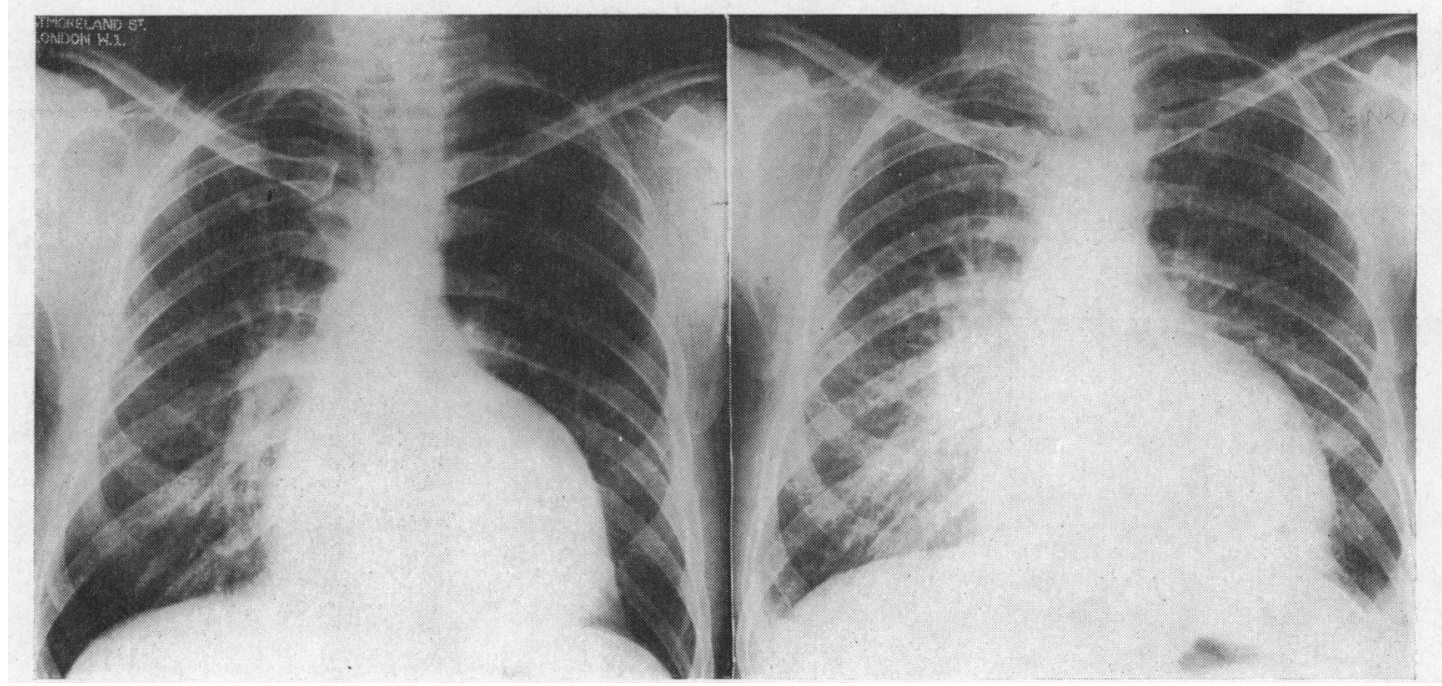

FIG. 1.-Chest radiograph of Patient 68 with corrected transposition and regurgitation of the systemic atrioventricular valve; left, in atrial fibrillation, and right, one day after electroconversion to sinus rhythm. Note the increase in heart size and pulmonary œdema in sinus rhythm.

the level of control was satisfactory. On the day following treatment, clinical examination, electrocardiogram, chest radiographs, and laboratory tests were repeated, and subsequently if they were abnormal.

\section{RESULTS}

Sinus rhythm was restored in 193 patients (88\%). The successfully treated patients included 154 of $180(86 \%)$ with atrial fibrillation, all $24(100 \%)$ with atrial flutter, 8 of 9 with atrial tachycardia, and all 7 with ventricular tachycardia.

Complications occurred in 32 patients $(14.5 \%)$ see Table II. Transient rhythm disturbances, which were noted immediately after the shock in 53 per cent, and superficial skin burns, which occurred in 5 per cent, have been excluded.

Serum Enzyme Levels. Significant increases in the serum enzyme levels of glutamic oxaloacetic transaminase and lactic dehydrogenase after treatment were observed in 20 patients (Table II); all except one had had atrial fibrillation. The underlying heart disease was post-operative rheumatic heart disease in 7, cardiomyopathy in 4 ( 3 alcoholic), and chronic ischæmic heart disease in 3 . No underlying heart disease could be determined in 6 ("lone" dysrhythmias).

A shock of 300-400 joules was used for conversion in 14 of the 20 patients, $200-300$ joules in 3 , and 50-150 joules in 3. An increase in the serum enzyme levels occurred as an isolated complication in 10 patients and was associated with other complications in 10 patients; they usually returned to pretreatment levels by five days, and always by seven days, after DC shock.

Increase in Heart Size and Pulmonary Oedema. A significant increase in the cardiothoracic ratio after treatment (Fig. 1) was found in 7 patients (Table II) and averaged 4 per cent (limits 1-6\%). The increase in heart size was invariably associated with pulmonary venous congestion on chest radiographs, and frank pulmonary œdema occurred in 2. Atrial fibrillation was present before DC shock in 6 and ventricular tachycardia in 8 . The underlying heart disease was chronic ischæmic heart disease in 3 , cardiomyopathy in 2 ( 1 alcoholic), rheumatic heart disease with moderate mitral stenosis in 1 , and corrected transposition with regurgitation of the systemic atrio-ventricular valve in 1 . A shock of $300-400$ joules was used for conversion in 5, 200 joules in 1, and 150 joules in 1. Additional complications were noted in 4 of the 7 patients; hypotension following the shock occurred in 2, significant increases in the levels of the serum enzymes in 3, and persistent multifocal ventricular ectopic beats in 1 .

The increase in heart size usually persisted for one to two days, but always responded to bed-rest, digitalis, and diuretics.

Hypotension. Hypotension was defined as a systolic blood pressure of $80 \mathrm{~mm}$. $\mathrm{Hg}$ or less for one hour or longer after electroconversion; it occurred in 7 patients, and was not present between induction of the anæsthesia and electroconversion. Atrial fibrillation was present before DC shock in 6 
TABLE II

COMPLICATIONS FOLLOWING DC SHOCK IN 32 OF 220 PATIENTS

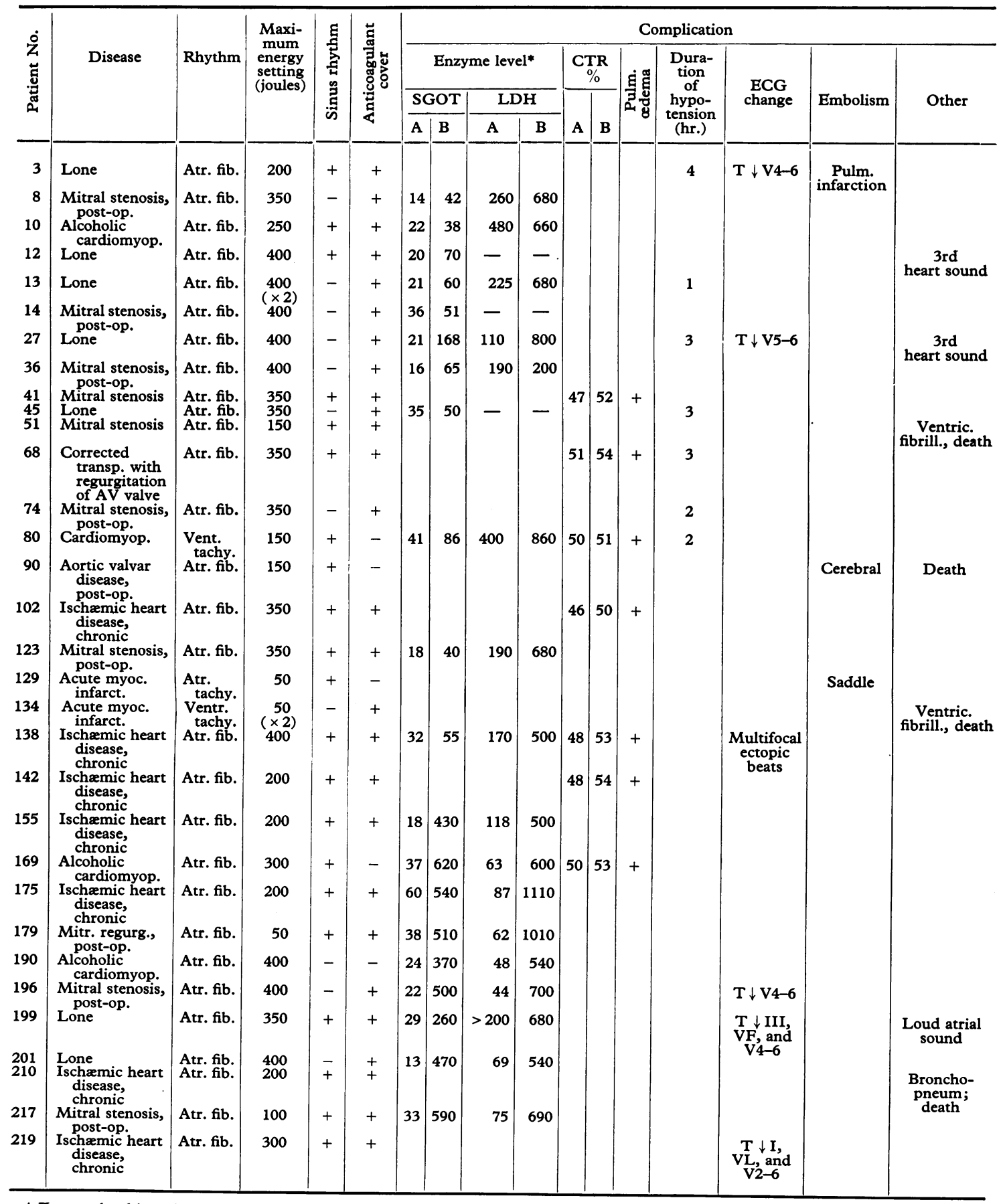




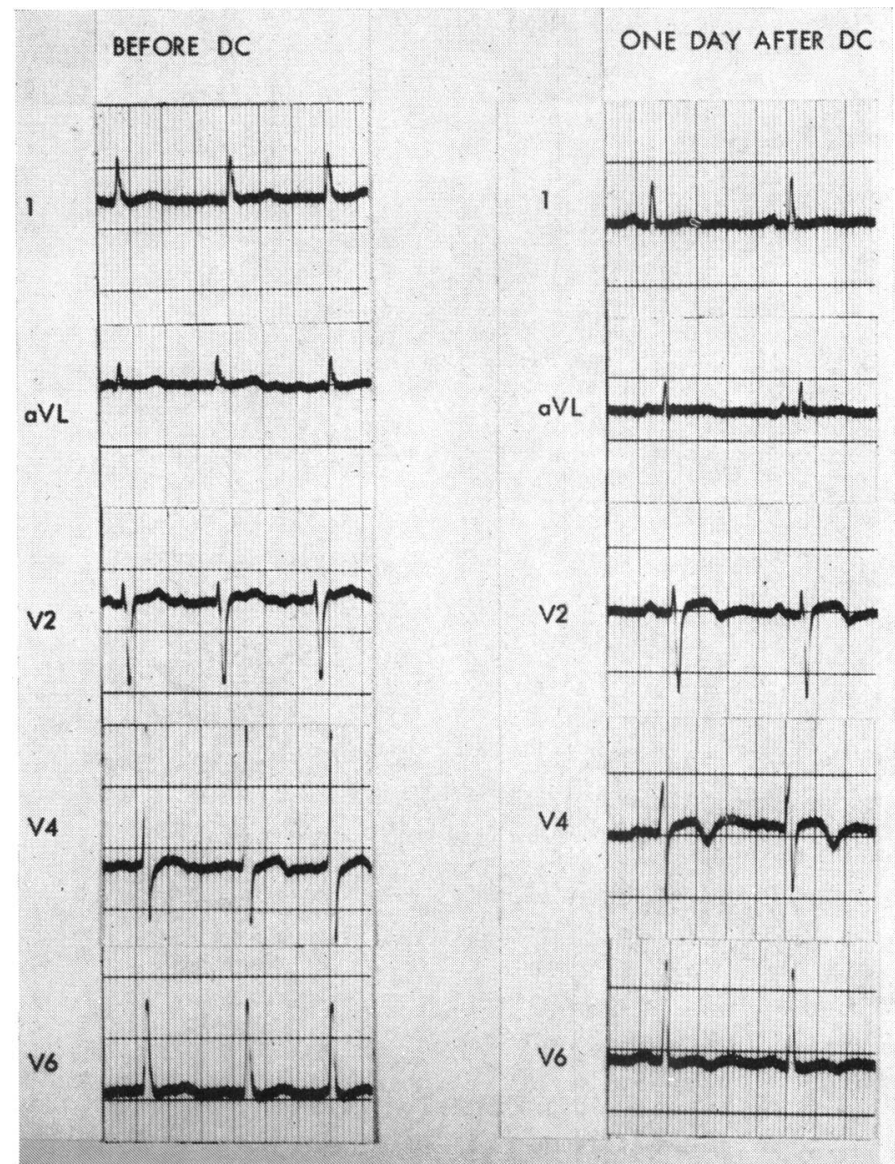

FIG. 2.-Electrocardiogram of Patient 219 in atrial fibrillation before DC shock and one day after electroconversion. The $T$ wave and $S-T$ segment changes recorded after DC shock were associated with increases in the serum levels of glutamic oxaloacetic transaminase and lactic dehydrogenase.

and ventricular tachycardia in 1 . In 4 patients no underlying heart disease was detected; post-operative mitral stenosis was present in 1 , corrected transposition in 1 , and cardiomyopathy in 1 . A shock of 350 or 400 joules was used in 5 patients, 200 in 1 and 150 joules in 1 . Additional complications (Table II) occurred in 2 of the 7 patients.

None of the patients required sympathomimetic drugs to raise the blood pressure which always became normal within four hours.

Electrocardiographic Changes. Significant changes, other than temporary disturbances of rhythm, were noted in the electrocardiograms of 6 patients following electroconversion. $T$ wave inversion (Fig. 2) was recorded in 5 patients and persistent multifocal ectopic beats (Fig. 3) in 1. Atrial fibrillation was the presenting dysrhythmia in all 6 patients and was apparently unassociated with underlying heart disease in 3; chronic ischæmic heart disease was present in 2, and post-operative rheumatic mitral stenosis in 1. A shock of 400 joules was used in 4 patients, 350 joules in 1 , and 200 joules in 1 . Additional complications were noted in 3 of the 6 patients (Table II). The electrocardiographic changes persisted for several days, and in 1 patient T wave inversion had remained up to 6 months.

Pulmonary and Systemic Embolism. Three patients developed embolism following DC shock (Table II). In the first patient, electroconversion under satisfactory anticoagulant control of "lone" atrial fibrillation (Evans and Swann, 1954) was achieved with 200 joules, and was followed on the day after treatment by inversion of the $T$ wave in leads V4-6 and pleuritic pain. The chest radiograph showed linear atelectasis of the right lung 


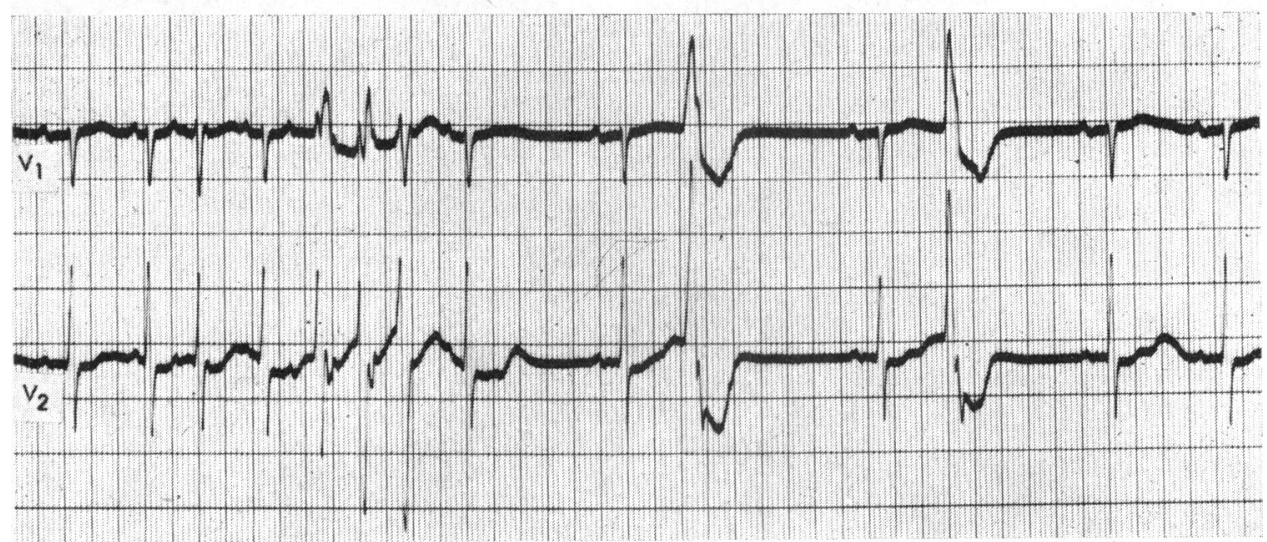

FIG. 3.-Electrocardiogram leads V1 and V2 of Patient 138 recorded one day after the electroconversion of atrial fibrillation to sinus rhythm. Multifocal ectopic beats are recorded.

(Fig. 4), which appeared to be due to pulmonary infarction, from which a good recovery was made. The second patient had had an aortic valvotomy 6 months before DC shock, and developed attacks of paroxysmal atrial tachycardia 6 weeks after the electroconversion of her atrial fibrillation. A cerebral embolus, which resulted in hemiplegia, occurred at the time of changing rhythms. Anticoagulants were not being used at the time of cerebral embolus. The third patient, a man of 55 years, developed atrial tachycardia in association with a recent cardiac infarction. Sinus rhythm was established following a single shock of 50 joules. Anticoagulant therapy was not being given at the time. Six hours later a saddle embolus occurred at the bifurcation of the aorta. The circulation was re-established following surgical removal of the embolus within two hours of its occurrence, and the patient made an uneventful recovery.

Deaths Following Treatment. Death was directly or indirectly related to direct current shock in 4 patients.

Patient 51 had atrial fibrillation in association with moderate mitral stenosis and was brought into sinus rhythm with a shock of 150 joules. Subsequently he was given quinidine sulphate (B.P.), $300 \mathrm{mg}$. 6-hourly.
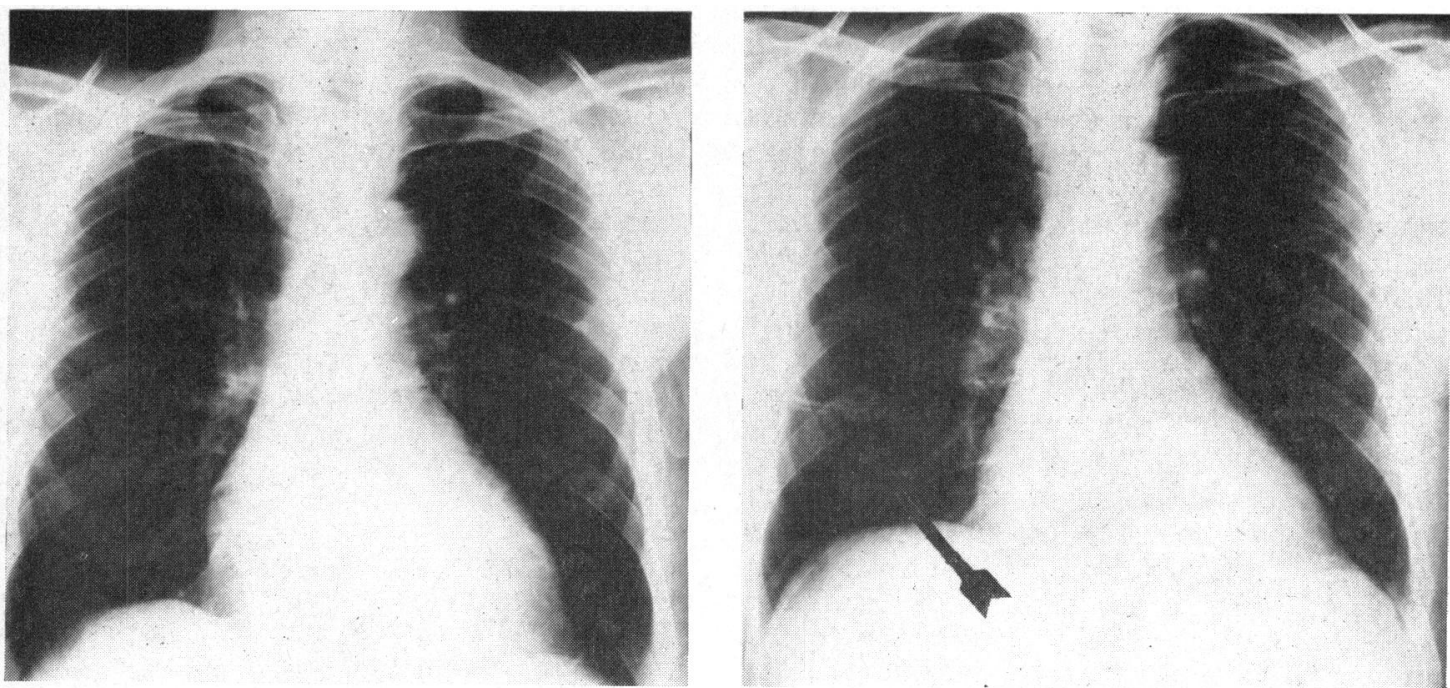

FIG. 4.-Chest radiograph of Patient 3: left, in atrial fibrillation, and right, one day later following the establishment of sinus rhythm by DC shock. Note linear atelectasis (arrowed) in sinus rhythm indicating pulmonary infarction. 
Ventricular fibrillation developed 36 hours after the shock, and failed to respond to emergency resuscitative measures.

Patient 90 died 7 months after the re-establishment of sinus rhythm. A cerebral embolus occurred 6 weeks after electroconversion and was followed by progressive cardiac and renal failure.

Patient 134 was referred from a considerable distance because of a ventricular tachycardia which had followed cardiac infarction 9 days before. It was resistant to drug therapy. Cardiac arrest supervened while preparations were being made for direct current shock without anæsthesia. A single unsynchronized shock resulted in sinus rhythm, but 24 hours later cardiac arrest recurred and failed to respond to resuscitative measures.

Patient 210 had atrial fibrillation in association with chronic ischæmic heart disease. Two weeks after the establishment of sinus rhythm, with a shock of 200 joules, bronchopneumonia developed and atrial fibrillation recurred. Death one day later was thought to be due to the toxic effects of the chest infection.

Other Complications. Two patients developed transient loud ventricular third heart sounds and one patient a loud atrial sound (Table II). In all 3 patients associated complications were noted.

\section{Discussion}

Despite the claim that complications following DC shock would result only from drugs that were used to maintain sinus rhythm (Lown, 1964), the present series of patients demonstrates that complications from the DC shock may be expected in 14.5 per cent. Complications were multiple in 14 of the 32 patients.

Changes in the levels of the serum enzymes were the commonest complication, occurring either as an isolated finding or in combination with other complications $(9 \%)$. These findings differ from those of Oram et al. (1963) who commented on the absence of raised enzyme levels following DC shock. In contrast, however, no fewer than 16 of 27 patients reported by Slodki et al. (1966) developed significant increases in the levels of serum enzymes. While raised levels of serum glutamic oxaloacetic transaminase do reflect myocardial damage (LaDue, Wróblewski, and Karmen, 1954), they could also indicate damage to skeletal muscle; raised levels of serum lactic dehydrogenase are more specific of myocardial damage (MacDonald, Simpson, and Nossal, 1957). It is significant that the raised levels of serum enzymes were frequently associated with other complications which could also be interpreted as evidence of myocardial damage (Table II). Furthermore, higher energy level settings of 300 joules or more were used in 70 per cent of the patients who were found to have raised serum enzymes following DC shock.

Pulmonary œdema and an increase in heart size following DC shock have been previously reported (Resnekov and McDonald, 1965), and confirmed (Honey, Nicholls, and Towers, 1965). This is not due to a sudden increase in the cardiac output with the establishment of sinus rhythm, for at rest the output of the heart is changed only slightly or not at all with the onset of sinus rhythm (Resnekov, 1965). Energy level settings of between 300 and 400 joules were used in 5 of the 7 patients, and significant changes in the levels of the serum enzymes or hypotension were often associated, suggesting that myocardial damage might be the cause. It is significant, however, that this complication occurs almost exclusively in those patients successfully reverted to sinus rhythm. Experimental work in dogs (L. Resnekov, P. Lord, G. E. Sowton, and J. Norman, 1965, unpublished data) has demonstrated considerable depression of mechanical function of the left atrium following direct current shock, and Logan et al. (1965) have shown that following electroconversion in man left atrial systole may be absent or inefficient despite normal " $a$ " waves being recorded in the right atrium. It is possible, therefore, that this complication results in part from imbalance between right and left atrial function. Any additional obstruction to flow across the mitral valve or left ventricular dysfunction would tend to aggravate the situation and result in the development of pulmonary œdema (Bell, 1966). Of particular interest are the accounts of Broch and Müller (1957) who demonstrated an increase in the pulmonary capillary pressure following the quinidine conversion of atrial fibrillation, and of Hollman and Nicholson (1966) who reported the onset of severe pulmonary odema which followed the spontaneous reversion to sinus rhythm of a 5-month episode of paroxysmal atrial fibrillation.

Acute breathlessness occurred in only 2 of the 7 patients, so that this complication may be overlooked unless chest radiographs are taken on the day following DC shock.

The embolic risk (1.4\%) compares favourably not only with published reports of this complication following DC shock (Morris et al., 1964; Hurst et al., 1964; Paulk and Hurst, 1965; Navab and La Due, 1965), but also with an incidence of 2 per cent following quinidine conversion (Goldman, 1959-60). Where there is a clear risk of embolism or thrombosis, as in patients with recent cardiac infarction, chronic ischæmic heart disease, a malfunctioning mitral valve, cardiomyopathy, or previous history of embolism, anticoagulant therapy using a coumarin 


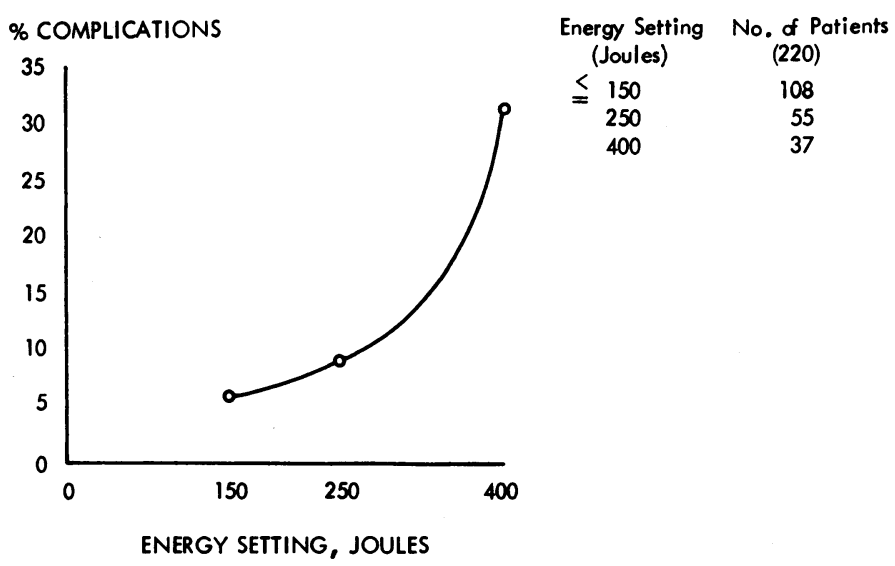

FIG. 5.-Energy level settings used in 220 patients treated by electroconversion plotted against complications. Note the increased incidence with higher energies.

derivative should be given, or heparin when the indication for DC shock is urgent. On the other hand, anticoagulant therapy for electroconversion does not appear to be necessary after successful mitral valvotomy or closure of an atrial septal defect.

Hypotension persisting for at least one hour following DC shock in 7 patients, and in 5 following the use of higher energy levels ( 350 or 400 joules), seems most likely to be associated with myocardial damage, as are the electrocardiographic changes that were found in the $T$ waves. Significant $T$ wave inversion (Fig. 2) occurred in 5 patients, and in 4, energy level settings of 350-400 joules were used. $T$ wave changes and S-T segment elevation have also been recorded by Killip (1963), Oram and Davies (1964), Sussman, Woldenberg, and Cohen (1964), Turner and Towers (1964), and by Szekely, Batson, and Stark (1966). Multifocal ectopic beats (Fig. 3) persisting for 36 hours followed a DC shock with an energy level setting of 400 joules in a further patient.

Ventricular fibrillation directly related to DC shock has not occurred in the present series; it is likely that the cause of delayed ventricular fibrillation in Patient 51 (Table II) was due to quinidine, and in Patient 134 to a severe myocardial infarction. Killip (1963), Lemberg et al. (1964), and Towers et al. (1965) have all reported ventricular fibrillation immediately after DC shock. Failure of synchronization, with the shock occurring during the vulnerable phase of ventricular repolarization, has been considered as a cause, but over-digitalization may be responsible (Rabbino, Likoff, and Dreifus, 1964; Ross, 1964). Nachlas et al. (1966) consider that delivering too small a current to the heart by DC shock is the important precipitating factor rather than a failure in synchronization.
Of the 32 patients who developed complications following DC shock, 19 (60\%) were given 300400 joules, and a further 6 patients 200 joules. In the total series of 220 patients, 57 were treated with an energy level setting of $300-400$ joules and 19 (33\%) of these developed complications; 163 patients were treated with $50-250$ joules and of these $13(8 \%)$ developed complications. The difference between the 2 groups is highly significant $(p<0.001)$. This increased incidence of complications following higher energy level settings seems important and is shown in Fig. 5.

It has already been demonstrated (Peleška, 1961) that myocardial damage may result from a discharging capacitor. Unlike alternating current where the waveform is determined by the power station, the waveform and magnitude of a capacitor discharge may be varied considerably by changes in the design of the circuit. The important electrical variables which relate to the clinical use of DC shock are: the capacitance of the condenser; the value of the inductance of the circuit; the resistance between the patient electrodes; the rise time of the current waveform.

A capacitor of 16 microfarads charged to a DC voltage by a variable transformer is incorporated in the Lown cardioverter, which was used in the present study, and discharges through an inductance coil of 100 millihenrys and across the resistance of the body over a mean time of 3.5 milliseconds to produce the slightly underdamped waveform shown in Fig. 6. The essential difference between DC and AC defibrillation is that though DC develops many times the power of $\mathrm{AC}$ it expends much less energy in doing so. Furthermore, the heat which is generated in a patient is less with a DC shock (Tedeschi 


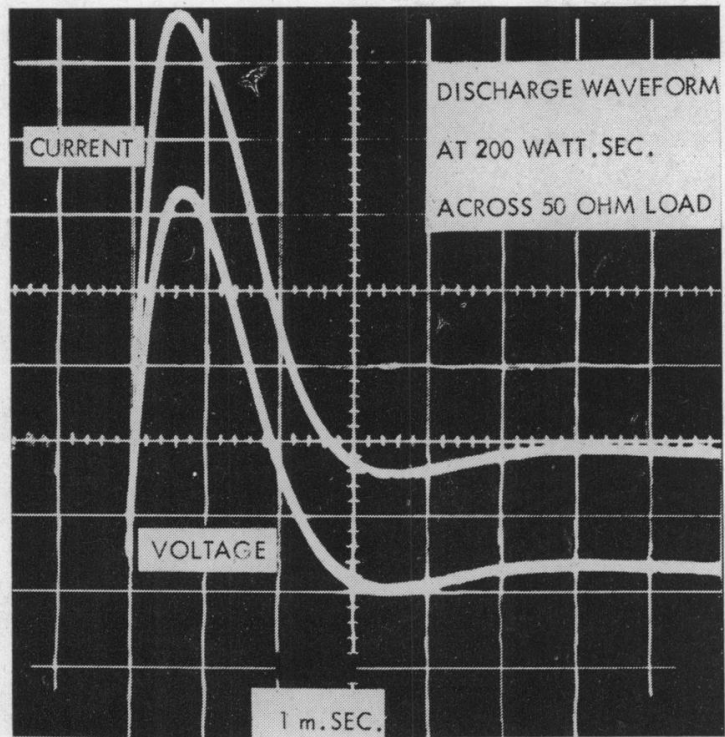

FIG. 6.-Slightly underdamped current and voltage waveform recorded by discharging the Lown cardioverter across a $50 \mathrm{ohm}$ load. Ringing is kept to a minimum.

and White, 1954), and ventricular function is less disturbed (Yarbrough, Ussery, and Whitley, 1964). Patient electrodes should always be large enough to prevent excessive central current density (Peleška, 1958).

The effect on the heart of the passage of electrical energy depends on the current rather than on the voltage (Ferris et al., 1936), and this is true for both AC and DC shocks (Nachlas et al., 1966). Currents of less than 1 amp. may cause fibrillation while those exceeding $1.5 \mathrm{amp}$. will stop fibrillation (Kouwenhoven et al., 1957). Only 10-30 per cent of the total current passes through the heart when the shock is delivered to the chest wall (Guyton and Satterfield, 1951), and thus electrical energies of between 50 and 400 joules may be required to defibrillate through the chest wall.

The skin and tissue resistance is less important with DC defibrillators than with AC defibrillators, but nevertheless does vary from patient to patient. Furthermore, it is well established that the electrical impedance alters with higher voltages (Hopps, 1964) so that the value will not be constant in any one patient but will tend to lessen as the energy level is increased should sinus rhythm not follow the first shock. If the defibrillation apparatus is considered in terms of a DC resistive circuit (Fig. 7), resistance $\left(R_{1}\right)$ between the inductance $(L)$ and the body $\left(R_{2}, R_{3}, R_{4},\right)$ may alter significantly because of a change in total body impedance, and this might be responsible for changes in the discharge waveform and in the current flowing across the heart.

It is clear, therefore, that even using apparatus of approved electrical design higher voltages and energies may cause changes that are outside the control of the operator.

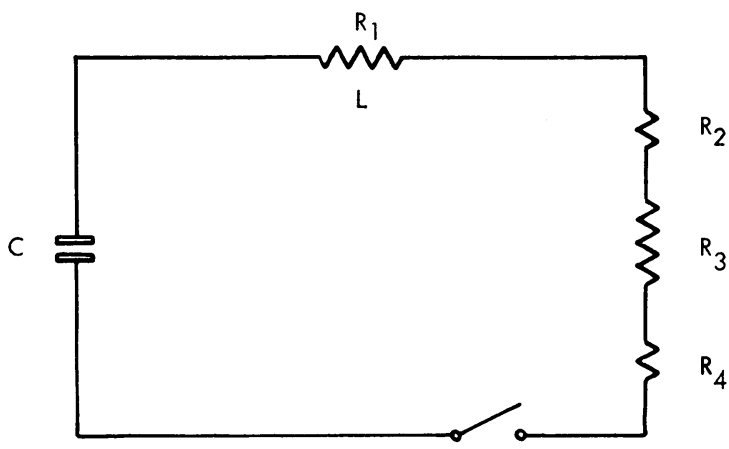

FIG. 7.-The Lown cardioverter considered in terms of a DC resistive circuit. The capacitor (C) discharges across an inductance $(L)$ of resistance $\left(R_{1}\right)$ and across the total body impedance which consists of resistance across the skin $\left(R_{2}\right.$ and $\left.R_{4}\right)$ and across the heart $\left(R_{3}\right)$-see text.

The series of patients presented shows that complications are related to the higher energy level settings. Patients with atrial fibrillation of whatever cause persisting for more than 5 years have only a 48 per cent chance of achieving sinus rhythm; 75 per cent of these will revert to the dysrhythmia within a period of time varying from minutes to 9 months following electroconversion (Resnekov, 1965). The increased incidence of complications in those patients with atrial fibrillation of longer duration is shown in Fig. 8. It is doubtful, therefore, whether energy level settings in excess of 300 joules are justified in patients presenting with longstanding dysrhythmias. Nevertheless, hæmodynamic benefit in sinus rhythm, especially on exercise, can be shown even in this group (Resnekov, 1965) so that each patient requires individual assessment. The higher energy level settings (300-400 joules) should only be used in those patients who have acute dysrhythmias resulting in serious hæmodynamic consequences and where the re-establishment of sinus rhythm is urgently required. $\mathrm{Al}-$ though it might be considered that patients with lone atrial fibrillation, small hearts, and at most very slight left atrial enlargement, would be ideal for DC defibrillation, our experience with 33 patients suggests the contrary. In 21 per cent sinus rhythm was not established (compared with $12 \%$ of failures in the other groups), complications to DC shock were noted in 25 per cent, and only 4 patients have re- 


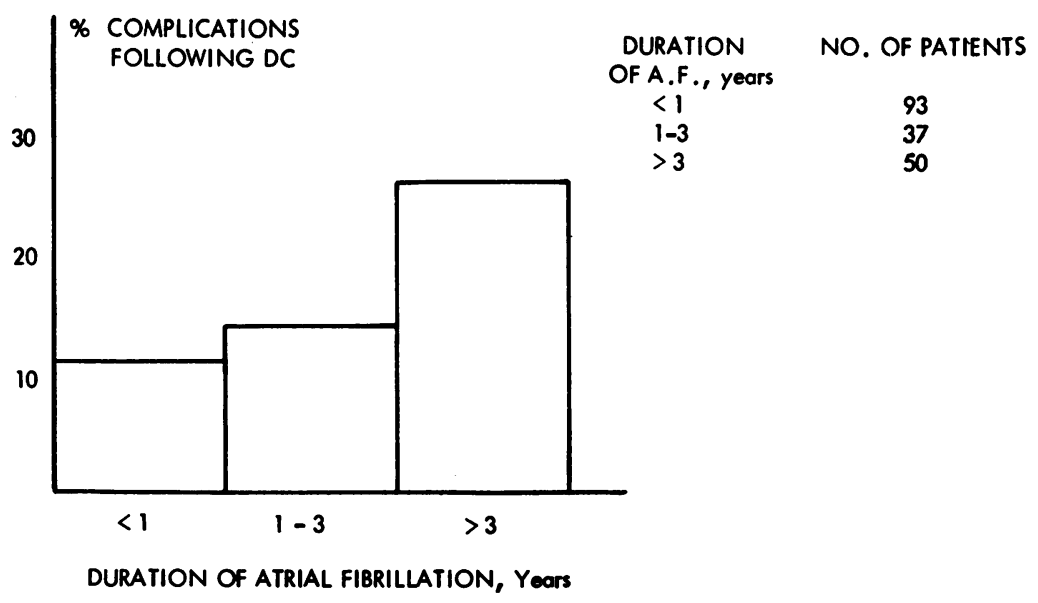

FIG. 8.-The duration of atrial fibrillation before DC shock in 180 patients shown against the percentage of complications which followed the shock. Note the increased incidence of complications when atrial fibrillation is of longer duration.

mained in sinus rhythm for a significant length of time. Similarly, patients with atrial fibrillation in association with chronic ischæmic heart disease have a high incidence of complications following DC shock $(37 \%)$, as do patients with atrial fibrillation in association with cardiomyopathy $(17 \cdot 5 \%$-Table III).

TABLE III

180 PATIENTS WITH ATRIAL FIBRILLATION TREATED BY DC SHOCK, SHOWING NUMBER DEVELOPING COMPLICATIONS

\begin{tabular}{l|c|c}
\hline \multicolumn{1}{c|}{ Heart disease } & $\begin{array}{c}\text { No. treated } \\
\text { by DC shock }\end{array}$ & $\begin{array}{c}\text { No. developing } \\
\text { complications }\end{array}$ \\
\hline Rheumatic & 101 & $11(11 \%)$ \\
Lone dysrhythmias & 33 & $7(21 \%)$ \\
Cardiomyopathy & 17 & $3(17.5 \%)$ \\
Ischæemic & 16 & $7(44 \%)$ \\
Congenital & 7 & 1 \\
Other & 6 & 0 \\
\hline Total & 180 & $29(16 \%)$ \\
\hline
\end{tabular}

When, in the management of cardiac dysrhythmias, a decision to restore sinus rhythm is made, phased direct current shock may at present be considered the method of choice for the following: in supraventricular and ventricular dysrhythmias requiring urgent treatment, including those following soon after myocardial infarction and cardiac operations; in atrial dysrhythmias following closure of atrial septal defects, which are often resistant to treatment with drugs; in atrial fibrillation following successful mitral valvotomy; in re-establishing sinus rhythm even if only to improve temporarily the hæmodynamic state in mitral regurgitation, following the insertion of prosthetic or homograft valves, and where resistant cardiac failure is associated with an atrial dysrhythmia; in all cases of atrial flutter that have not readily returned to sinus rhythm with digitalis; and in atrial tachycardia which has not responded to simple measures such as vagal stimulation. In the above situations energy level settings of 50-400 joules may be used, in increments of 50 joules, and the outcome of treatment is satisfactory. However, in our experience, relapses are particularly frequent and complications are common, when phased direct current shock is used to treat chronic atrial fibrillation of more than 3 years' duration, of whatever cause, atrial fibrillation in ischæmic heart disease, and atrial fibrillation in association with a cardiomyopathy. It is considered that energy level settings in these cases should not exceed 300 joules.

The treatment of "lone" atrial fibrillation by direct current shock has been particularly disappointing, and the method should probably be seldom used in such patients. Furthermore, it is not indicated in patients with rheumatic heart disease, unless the natural history of the disease has been altered by heart operation.

\section{SUMMARY}

There were 220 consecutive patients with atrial dysrhythmias and ventricular tachycardia who were treated by phased direct current shock; complications followed in 14.5 per cent.

Increases in the serum levels of glutamic oxaloacetic transaminase and lactic dehydrogenase 
occurred in 20 of the 220 patients, episodes of pulmonary œdema in 2 , enlargement of the heart and pulmonary venous congestion in 7 , electrocardiographic changes in 6, and pulmonary or systemic emboli in 3. Death was directly or indirectly related to direct current shock in 4 patients.

Complications were related to higher energy level settings especially those exceeding 300 joules.

Patients most likely to develop complications were those with dysrhythmias in association with ischæmic heart disease and cardiomyopathy, and when atrial fibrillation of whatever cause was present for more than 3 years. Patients with lone atrial fibrillation and flutter also had a high incidence of complications.

Indications for phased direct current in the management of cardiac dysrhythmias are reviewed, and conclusions drawn regarding energy level settings to be used.

It is suggested that attempts should seldom be made to convert lone atrial fibrillation and flutter by direct current shock.

Important electrical variables in the apparatus for phased direct current shock are reviewed.

\section{REFERENCES}

Bell, H. E. (1966). Direct-current shock for atrial fibrillation. Lancet, 2, 911.

Berger, L., and Broida, D. (1957, 1960). Colorimetric determination of lactic dehydrogenase. Technical bulletin No. 500. Sigma Chemical Company, St. Louis.

Broch, O. J., and Müller, O. (1957). Hæmodynamic studies during auricular fibrillation and after restoration of sinus rhythm. Brit. Heart f., 19, 222.

Danzer, C. S. (1919). The cardiothoracic ratio; an index of cardiac enlargement. Amer. F. med. Sci., 157, 513.

Dawson, J. B. (1960). The E.S.R. in a new dress. Brit. med. $., 1,1697$.

Evans, W., and Swann, P. (1954). Lone auricular fibrillation. Brit. Heart F., 16, 189.

Ferris, L. P., King, B. G., Spence, P. W., and Williams, H. B. (1936). Effect of electrical shock on the heart. Elect. Engng (N.Y.), 55, 498.

Gilston, A., Fordham, R., and Resnekov, L. (1965). Anæsthesia for direct current shock in the treatment of cardiac arrhythmias. Brit. F. Anasth., 37, 533.

Goldman, M. J. (1959-60). The management of chronic atrial fibrillation: indications for and method of conversion to sinus rhythm. Progr. cardiovasc. Dis., 2, 465.

Guyton, A. C., and Satterfield, J. (1951). Factors concerned in electrical defibrillation of the heart, particularly through the unopened chest. Amer. F. Physiol., 167, 81.

Hollman, A., and Nicholson, H. (1966). Direct-current shock for atrial fibrillation. Lancet, $2,801$.

Honey, M., Nicholls, T. T., and Towers, M. K. (1965). Pulmonary odema following direct-current defibrillation. Lancet, 1, 765.

Hopps, J. A. (1964). Cardiac resuscitation-the present status of defibrillation and stimulation techniques. Canad. med. Ass. F., 90, 122.
Hurst, J. W., Paulk, E. A., Jr., Proctor, H. D., and Schlant, R. C. (1964). Management of patients with atrial fibrillation. Amer. F. Med., 37, 728.

Killip, T. (1963). Synchronized DC precordial shock for arrhythmias. F. Amer. med. Ass., 186, 1.

Kouwenhoven, W. B., Milnor, W. R., Jude, J. R., Knickerbocker, G. G., and Chesnut, W. R. (1957). Closed chest defibrillation of the heart. Surgery, 42, 550.

LaDue, J. S., Wróblewski, F., and Karmen, A. (1954). Serum glutamic oxaloacetic transaminase activity in human acute transmural myocardial infarction. Science, 120, 497.

Lemberg, L., Castellanos, A., Swenson, J., and Gosselin, A. (1964). Arrhythmias related to cardioversion. Circulation, 30, 163.

Logan, W. F. W. E., Rowlands, D. J., Howitt, G., and Holmes, A. M. (1965). Left atrial activity following cardioversion. Lancet, $2,471$.

Lown, B. (1964). "Cardioversion" of arrhythmias (II). Mod. Conc. cardiovasc. Dis., 33, 869.

—, Neuman, J., Amarasingham, R., and Berkovits, B. V. (1962). Comparison of alternating current with direct current electroshock across the closed chest. Amer. $\mathcal{F}$. Cardiol., 10, 223.

McDonald, E. L., and Resnekov, L. (1965). Atrial fibrillation. In Resuscitation and Cardiac Pacing, ed. G. Shaw, G. Smith, and T. J. Thomson, p. 140. Cassell, London.

McDonald, L., Resnekov, L., and O'Brien, K. (1964). Directcurrent shock in treatment of drug-resistant cardiac arrhythmias. Brit. med. F., 1, 1468.

MacDonald, R. P., Simpson, J. R., and Nossal, E. (1957). Serum lactic dehydrogenase-a diagnostic aid in myocardial infarction. F. Amer. med. Ass., 165, 35.

Morris, J. J., Jr., Kong, Y., North, W. C., and McIntosh, H. D. (1964). Experience with "cardioversion" of atrial fibrillation and flutter. Amer. F. Cardiol., 14, 94.

Nachlas, M. M., Bix, H. H., Mower, M. M., and Sieband, M. P. (1966). Observations on defibrillators, defibrillation and synchronized countershock. Progr. cardiovasc. Dis., 9, 64.

Navab, A. and La Due, J. S. (1965). Postconversion systemic arterial embolism. Amer. F. Cardiol., 16, 452.

Oram, S., and Davies, J. P. H. (1964). Further experience of electrical conversion of atrial fibrillation to sinus rhythm: analysis of 100 patients. Lancet, 1, 1294.

$\longrightarrow,-$ Weinbren, I., Taggart, P., and Kitchen, L. D. (1963). Conversion of atrial fibrillation to sinus rhythm by direct-current shock. Lancet, $2,159$.

Owren, P. A. (1959). Thrombotest: a new method for controlling anticoagulant therapy. Lancet, 2, 754.

Paulk, E. A., Jr., and Hurst, J. W. (1965). Clinical problems of cardioversion. Amer. Heart f., 70, 248.

Peleška, B. (1958). La défibrillation transthoracique et directe à haute tension. Anesth. et Analg., 15, 238. (1961). A high-voltage defibrillator and the theory of high-voltage defibrillation. In Proceedings Third International Conference on Medical Electronics, London, 1960 , p. 265.

Rabbino, M. D., Likoff, W., and Dreifus, L. S. (1964). Complications and limitations of direct-current countershock. 7. Amer. med. Ass., $190,417$.

Resnekov, L. (1965). Synchronised capacitor discharge in the management of cardiac arrhythmias with particular reference to the significance of atrial systole. M. D. Thesis, University of Cape Town.

- , and McDonald, L. (1965). Pulmonary œdema following treatment of arrhythmias by direct-current shock. Lancet, 1, 506. 
Ross, E. M. (1964). Cardioversion causing ventricular fibrillation. Arch. intern. Med., 114, 811.

Sigma-Frankel Method (1956, 1961). A simplified method for the colorimetic determination of glutamic oxaloacetic and glutamic pyruvic transaminases. Sigma technical bulletin No. 505 . Sigma Chemical Company, St. Louis.

Slodki, S. J., Falicov, R. E., Katz, M. J., West, M., and Zimmerman, H. J. (1966). Serum enzyme changes following external direct current shock therapy for cardiac arrhythmias. Amer. F. Cardiol., 17, 792.

Sussman, R. M., Woldenberg, D., and Cohen, M. (1964). Myocardial changes immediately following direct current shock for termination of atrial fibrillation. $\mathrm{Ab}$ stracts, 7th Inter American Congress of Cardiology, Montreal, p. 166.
Szekely, P., Batson, G. A., and Stark, D. C. C. (1966). Direct current shock therapy of cardiac arrhythmias. Brit. Heart f., 28, 366.

Tedeschi, C. G., and White, C. W., Jr. (1954). A morphologic study of canine hearts subjected to fibrillation, electrical defibrillation and manual compression. Circulation, 9, 916.

Towers, M. K., Gibson, R. V., Burn, J. M. B., and Monro, J. A. (1965). The termination of cardiac arrhythmias by direct current shock. Postgrad. med. F., 41, 120.

Turner, J. R. B., and Towers, J. R. H. (1964). Myocardial damage from therapeutic electric shock. Lancet, 1, 1396. Yarbrough, R., Ussery, G., and Whitley, J. (1964). A comparison of the effects of A.C. and D.C. countershock on ventricular function in thoracotomized dogs. Amer. F. Cardiol., 14, 504. 